\title{
Zoledronic acid negatively affects the expansion of in vitro activated human NK cells and their cytolytic interactions with Ewing sarcoma cells
}

\author{
SARAH-KRISTIN MUELLER, BIANCA ALTVATER, CHRISTIANE CHEN, SAREETHA KAILAYANGIRI, \\ MARTINA AHLMANN, UTA DIRKSEN, HERIBERT JUERGENS and CLAUDIA ROSSIG \\ Department of Pediatric Hematology and Oncology, University Children's Hospital Muenster, Muenster, Germany
}

Received December 10, 2012; Accepted January 21, 2013

DOI: $10.3892 / 0 r .2013 .2350$

\begin{abstract}
Disseminated Ewing sarcoma remains a fatal disease despite advanced multimodal treatment regimens. Immunotherapies as well as novel drugs and biologicals are currently being explored to eliminate minimal residual disease after conventional therapy thereby rescuing patients at a high risk for relapse. Insights into the interactions between novel therapies provide the basis for the development of effective combination strategies. We investigated the effects of the aminobisphosphonate zoledronic acid (ZA) on the in vitro expansion of human natural killer (NK) cells and their cytolytic activity against Ewing sarcoma cells. ZA significantly impaired the in vitro expansion of activated NK cells from both healthy donors and Ewing sarcoma patients in a dosedependent manner. Expression of differentiation markers and activating receptors was unaffected by the drug. Activated NK cells from both healthy donors and patients had potent degranulation responses to Ewing sarcoma cells. In the presence of ZA at concentrations reflecting pharmaceutical serum levels, the in vitro antitumor activity of NK cells from Ewing sarcoma patients was significantly impaired. We conclude that ZA can impede in vitro NK cell expansion and cytolytic NK cell responses to Ewing sarcoma. These observations raise caution against the combination of adoptive NK cell transfer with ZA maintenance therapy in Ewing sarcoma. Future studies aim to identify potentiating interactions of novel drugs with cellular therapies.
\end{abstract}

\section{Introduction}

Ewing sarcoma is an aggressive cancer of bone. Successful therapy requires a multimodal strategy combining systemic

Correspondence to: Professor Claudia Rossig, Department of Pediatric Hematology and Oncology, University Children's Hospital Muenster, Albert Schweitzer Campus 1, D-48149 Muenster, Germany E-mail: rossig@uni-muenster.de

Key words: aminobisphosphonates, cellular immunotherapy, NK cells multiagent chemotherapy with local treatment (1). Current 3 -year event-free survival ranges between $70 \%$ in patients with localized disease and good response to chemotherapy and only $25-30 \%$ in patients with skeletal metastases. Novel therapies are needed to eliminate residual disease after conventional treatment and prevent disease recurrence. One example of a conceptually novel non-cytotoxic drug is the bisphosphonate compound zoledronic acid (ZA). Bisphosphonates are a class of drugs that inhibit osteoclast activity and bone resorption and are widely used in patients with osteolytic skeletal disorders (2). Based on the rationale that ZA may interfere with stimulatory interactions between the bone microenvironment and tumor cells and on observations of direct antiproliferative effects against tumor cells (3-5), the drug was also evaluated for the treatment of primary and metastatic bone tumors. As expected, ZA demonstrated clinical antitumor activity in multiple myeloma (6) and osteosarcoma (7) and against (micro)metastatic bone and/or bone marrow disease in solid tumors $(8,9)$. In preclinical studies in Ewing sarcoma, ZA was found to inhibit in vivo tumor growth both alone and in synergism with chemotherapies $(4,5)$, and initial clinical reports suggest that ZA combined with chemotherapy may be effective in refractory disease (10). The drug has now entered randomized clinical evaluation to improve overall survival as an add-on therapy in localized disease (4).

In a parallel development, cellular therapies have emerged as promising novel modalities for cancer treatment (11). Among pediatric solid tumors, Ewing sarcoma cells were found to be particularly sensitive to lysis by activated natural killer (NK) cells in vitro (12). NK cells are innate effector lymphocytes that provide a first-line defense against viral infection and tumor cells. Thus, NK cell therapies may have therapeutic benefit in Ewing sarcoma without additive toxicity. Modulatory or synergistic interactions between novel drugs and immunotherapies have only begun to be investigated. Antiapoptotic proteins, kinase inhibitors and epigenetic agents can sensitize cancer cells to antigen-specific immunotherapies and reverse immune escape (13-17). On the other hand, various non-cytotoxic anticancer drugs were found to negatively interfere with critical lymphocyte and antigen-presenting functions and thereby conflict with rational combinations of the two strategies $(18,19)$. 
Apart from their antitumor and antiresorptive activities, ZA and other bisphosphonates have potent immunomodulating effects. At clinically relevant concentrations, these agents were found to induce specific activation and IL-2dependent proliferation of a peripheral blood lymphocyte subset, $\gamma \delta$ T cells (20). Moreover, ZA can inhibit the activation of monocyte-derived dendritic cells (21). The immune effects of ZA are further documented by the clinical inflammatory syndrome that occurs in many patients upon first doses and is associated with a transient decrease in the number of lymphocytes circulating in peripheral blood $(22,23)$. Through indirect mechanisms, ZA was found to enhance NK cell effector functions (24), supporting the combination of the two strategies. In the present study, we explored the direct in vitro effects of ZA on expansion, phenotype and cytolytic activity of human NK cells in Ewing sarcoma.

\section{Materials and methods}

Cell lines. The identity of all cancer cell lines was confirmed by short tandem repeat (STR) profiling. The Ewing sarcoma cell lines TC-71 and CADO-ES1 were obtained from DSMZ (Braunschweig, Germany). VH-64 and WE-68 cells were gifts from Frans van Valen's Laboratory at the Institute of Experimental Orthopedics of the University of Muenster, Germany. These cell lines were characterized by the EuroBoNeT consortium (25). Tumor cells were cultured in collagen-coated $25-\mathrm{cm}^{2}$ tissue culture flasks (VH-64, WE-68, CADO-ES1) or in uncoated flasks (TC-71) in RPMI-1640 medium (Invitrogen, Darmstadt, Germany), supplemented with $10 \%$ heat-inactivated fetal calf serum (FCS) (Thermo Fisher, Bonn, Germany) and $2 \mathrm{mM}$ L-glutamine and maintained at $37^{\circ} \mathrm{C}$ in $5 \% \mathrm{CO}_{2}$. $\mathrm{K} 562$ (ATCC) is a human erythroleukemia cell line that is sensitive to lysis by NK cells. Generation of the K562-mb15-41BBL stimulator cells was previously described (26). The human myeloid ML-2 cell line (ATCC) was used as a control target.

In vitro expansion of human NK cells. Approval for using peripheral blood samples of both healthy donors and pediatric sarcoma patients was obtained from the University of Muenster Board of Ethics. Peripheral blood mononuclear cells (PBMCs) were purified by density gradient centrifugation and resuspended in RPMI-1640 medium, supplemented with $10 \%$ FCS and $2 \mathrm{mM}$ L-glutamine (RPMI culture medium). The cells were seeded at $1 \times 10^{6} /$ well in a 24 -well tissue-culture plate in the presence of $40 \mathrm{IU} / \mathrm{ml}$ recombinant human IL-2 (rhIL-2) (Proleukin; Chiron, Emeryville, CA, USA) in RPMI-1640 and $10 \%$ FCS and stimulated once with $0.75 \times 10^{6}$ irradiated (120 Gy) K562-mb15-41BBL stimulator cells, as described by Imai et al (26). TCR $\gamma \delta$-expressing T cells were depleted by magnetic cell sorting using the anti-TCR $\gamma \delta$ MicroBead kit (Miltenyi Biotec, Bergisch Gladbach, Germany).

Flow cytometry. For immunophenotyping, lymphocytes were stained with fluorescence-labeled anti-human antibodies against the following surface molecules: CD3, CD4, CD56, CD16, CD137 (4-1BB), NKG2D, NKG2A, NKG2C, CD94, CD57, 2B4 (CD244), DNAM-1 (CD226), NKp30, NKp44, $\mathrm{NKp} 46, \mathrm{TCR} \gamma \delta$ for $30 \mathrm{~min}$ at $4^{\circ} \mathrm{C}$. Anti-NKG2A and anti-
NKG2C antibodies were from R\&D Systems (Minneapolis, MN, USA). All others were from BD Biosciences (Heidelberg, Germany). Cells were analyzed using a FACSCanto cytometer (BD Biosciences).

CD107a assay. Degranulation responses were assessed by flow cytometric analysis of CD107a expression after a 4-h co-incubation with target cells. Co-incubations were performed in the presence of PE-labeled anti-human CD107a antibody (BD Biosciences) and $2 \mu \mathrm{M}$ monensin (Sigma, Munich, Germany). The NK cells were washed and stained with FITC-labeled anti-CD56 and PerCP-labeled anti-CD3 antibody, followed by analysis of cells within the $\mathrm{CD}^{-} 6^{+} \mathrm{CD}^{-}$gate.

Statistics. The Student's t-test was used to test whether the means in each set of values differed significantly, assuming two possible tails as well as unequal variance. A P-value $<0.05$ was defined as indicative of statistical significance. Values depict the means \pm standard deviation unless otherwise stated.

\section{Results}

Ewing sarcoma cells effectively induce NK cell degranulation responses. First, we assessed the capacity of individual Ewing sarcoma cell lines to functionally interact with in vitro activated and expanded human NK cells. CD107a upregulation corresponds to NK cell degranulation (27) and was used as a functional marker for cytolytic activity. PBMCs from three healthy donors were stimulated with irradiated K562 cells that had been gene-modified to express membrane-bound IL-15 and 41BB ligand, as described by Imai et al (26), and expanded in the presence of low-dose rhIL-2 for 12 days. This resulted in a mean 34.5 \pm 8.3 -fold increase in $\mathrm{CD}^{2} 6^{+} \mathrm{CD} 3^{-} \mathrm{NK}$ cells among the stimulated bulk populations on day 12 of culture (range, 27.8-43.7) and a mean purity of $66.8 \pm 11.9 \%$ (range, 53.1-74.2\%). Expanded NK cells from all donors were highly responsive to the NK cell-sensitive target cell line K562, while the NK cell-resistant leukemia ML2 cell line failed to induce degranulation responses above the background of the medium alone (Fig. 1A). At a 1:1 stimulator-to-responder cell ratio, VH-64, WE-68 and TC-71 Ewing sarcoma cells effectively induced CD107a upregulation responses in all three donors, with $44.6 \pm 16.5 \%$ (range, 23.3-65.2\%), $23.7 \pm 11.2 \%$ (range, $8.7-34.5 \%$ ) and $34.7 \pm 17.9 \%$ (range, 16.2 $53.9 \%$ ) CD107a-expressing cells within the $\mathrm{CD}^{2} 6^{+} \mathrm{CD} 3^{-} \mathrm{NK}$ cell gate, respectively. While degranulation responses to VH-64 cells were comparable to K562 cells in all donors, TC-71 and WE-68 cells induced variable responses among the three donors. Cado-ES-1 Ewing sarcoma cells failed to induce NK cell activation above the medium control in all donors (4.6 $\pm 3.7 \%$; range, 0.8-9.9\%). Specific degranulation responses to $\mathrm{VH}-64$ cells were maintained with reduced stimulator-to-responder cell ratios of $0.5: 1$ and even $0.1: 1$ (Fig. 1B). These results confirm that Ewing sarcoma cells can be highly efficient activators of allogeneic NK cells. Subsequent experiments were performed at the lowest ratio of 0.1:1 unless otherwise stated, and the NK cell-sensitive cell lines VH-64 and WE-68 were used as targets. 
A

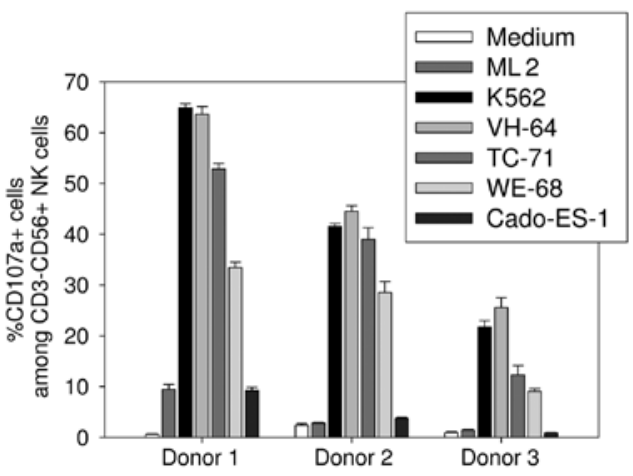

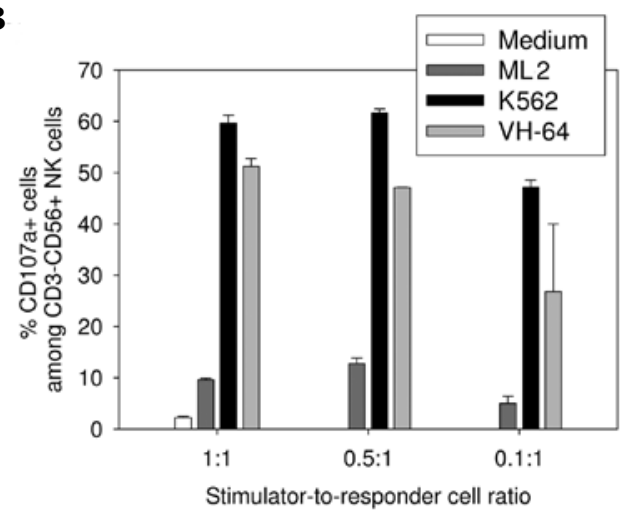

Figure 1. Ewing sarcoma cell lines induce potent NK cell degranulation responses. (A) The percentages of CD107a-expressing degranulating NK cells were determined by flow cytometry after a 4-h co-incubation of in vitro activated NK cells from three healthy donors with NK cell-sensitive (K562) and control (ML2) target cells, and with the Ewing sarcoma cell lines VH-64, TC-71, WE-68 and Cado-ES-1, respectively, at stimulator-to-responder cell ratio of 1:1 or in the presence of medium alone. To exclude residual non-NK lymphocytes within the cultures from analysis, the gate was set on $\mathrm{CD}^{+} / \mathrm{CD}^{-}$cells. (B) Percentages of CD107a-expressing cells among CD56 ${ }^{+}$NK cells in response to K562, ML2 and VH-64 cells and in the presence of medium alone at decreasing stimulator-to-responder cell ratios. Bars in the histograms represent means and standard deviations of results from triplicate wells.

Table I. Surface expression density of cell receptors on NK cells expanded in the presence or absence of aminobisphosphonate zoledronic acid.

\begin{tabular}{lcccccc}
\hline & \multicolumn{2}{c}{ Without ZA } & & \multicolumn{2}{c}{ With 1 $\mu \mathrm{M} \mathrm{ZA}$} \\
\cline { 2 - 3 } Marker & MFI (means \pm SD) & Range & & MFI (means \pm SD) & Range & P-value \\
\hline CD56 & $3210 \pm 2133$ & $1875-5670$ & & $2764 \pm 409$ & $2292-3022$ & $\mathrm{~ns}$ \\
CD57 & $160 \pm 47$ & $130-214$ & & $138 \pm 24$ & $113-161$ & $\mathrm{~ns}$ \\
CD244 (2B4) & $2007 \pm 546$ & $1599-2627$ & & $1998 \pm 13$ & $1568-2487$ & $\mathrm{~ns}$ \\
NKG2D & $5376 \pm 885$ & $4378-6065$ & & $6187 \pm 2623$ & $3213-8172$ & $\mathrm{~ns}$ \\
CD137 (4-1BBL) & $105 \pm 18$ & $85-118$ & & $105 \pm 13$ & $90-109$ & $\mathrm{~ns}$ \\
CD226 (DNAM-1) & $3841 \pm 461$ & $3524-4370$ & & $3906 \pm 363$ & $3641-4319$ & $\mathrm{~ns}$ \\
NKp46 & $380 \pm 198$ & $179-574$ & & $257 \pm 80$ & $165-312$ & $\mathrm{~ns}$ \\
NKp44 & $128 \pm 40$ & $97-174$ & & $143 \pm 75$ & $60-205$ & $\mathrm{~ns}$ \\
NKp30 & $4025 \pm 668$ & $3510-4780$ & & $3923 \pm 1643$ & $2049-5119$ & $\mathrm{~ns}$ \\
\hline
\end{tabular}

The median fluorescence intensity (MFI) of expression was determined within the CD56 ${ }^{+} \mathrm{CD} 3-$ lymphocyte gate following 10 days of NK cell expansion in the absence or presence of $1 \mu \mathrm{M}$ ZA. Shown are the means and standard deviations (SD) of experiments with three donors. ns, statistically not significant. ZA, aminobisphosphonate zoledronic acid.

Zoledronic acid impairs the in vitro expansion of NK cells from healthy donors whereas the cytolytic responses to tumor cells are essentially maintained. To investigate the effects of ZA on the in vitro expansion and functionality of human NK cells, NK cells were in vitro activated and expanded from PBMCs of five healthy donors as described above, in the absence or presence of increasing concentrations of ZA. These concentrations correspond to plasma levels obtained in patients after ZA infusion (28). NK cell expansion was significantly diminished in the presence of ZA in a dose-dependent manner compared to the ZA-free medium control (Fig. 2A). Substantial interdonor variability was observed; whereas addition of $10 \mu \mathrm{MZA}$ to the culture medium almost completely prevented NK cell expansion in three donors, expansion rates of 76.6 and $79.2 \%$ of controls, respectively, were obtained under the same conditions in the two other donors.

Next, we analyzed the phenotypes and NK cell receptor expression of NK cells expanded from three healthy donors in the presence or absence of $\mathrm{ZA}$ by gating on $\mathrm{CD} 56^{+} \mathrm{CD} 3$ lymphocytes and flow cytometryic analysis. Our in vitro stimulation method preferentially expanded NK cells with a CD56 ${ }^{\text {bright }}$ phenotype (Fig. 2B). Under the two culture conditions, equal proportions of NK cells expressed CD57, a marker of highly mature and differentiated NK cells (29). Over $95 \%$ of expanded NK cells co-expressed the activating receptors NKG2D and DNAM-1 (CD226), which have both been implicated in the recognition of target cells via specific ligands, as well as the (co)stimulatory receptor 2B4 (CD244) and the activating receptors NKp30 and NKp46, as well as NKp44 and CD94/NKG2C (data not shown), regardless of the presence or absence of ZA (Fig. 2B). CD94/NKG2A heterodimers, which have inhibitory function, were also equally expressed under all culture conditions. Median fluorescence intensities of expression of all of these receptors did not significantly vary between the two populations (Table I). 

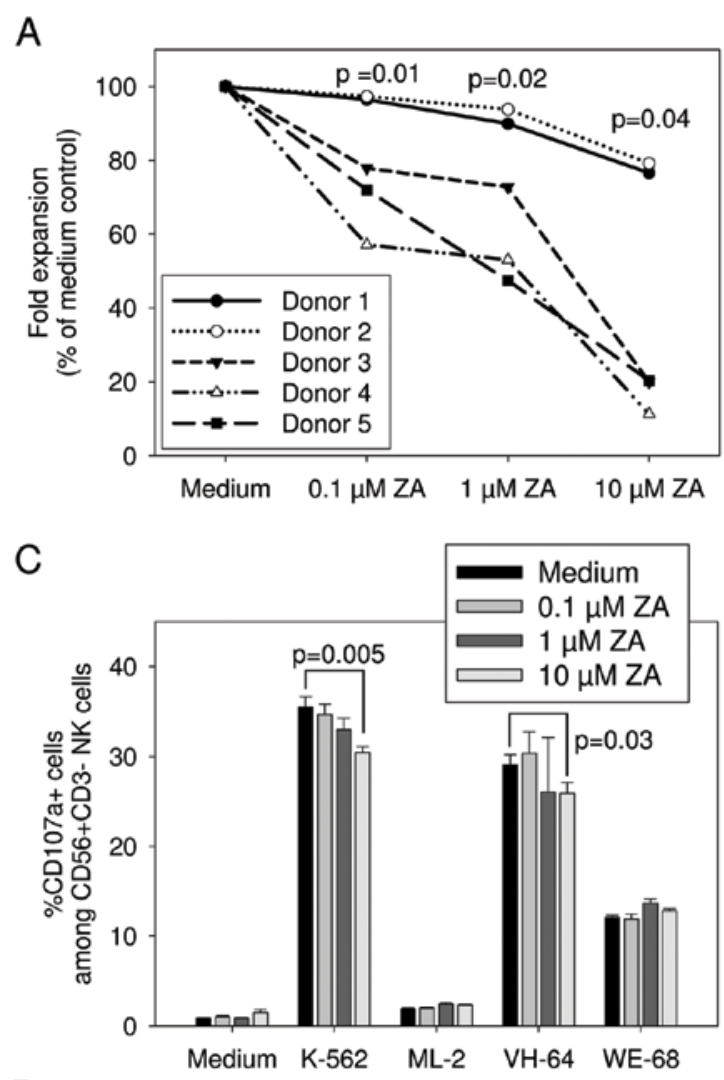

D

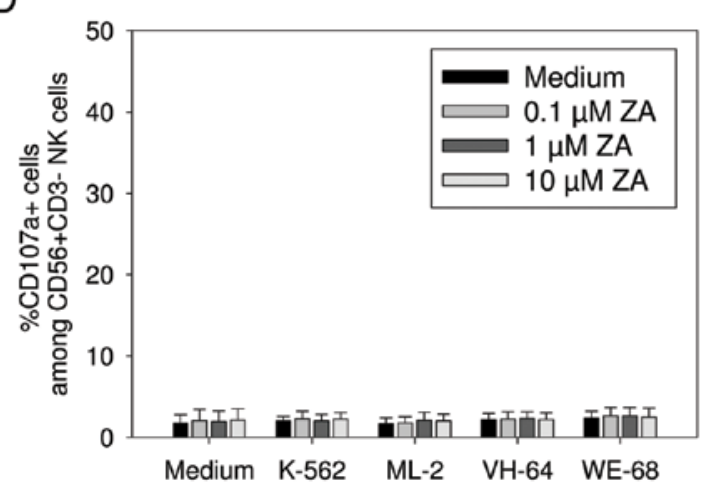

B

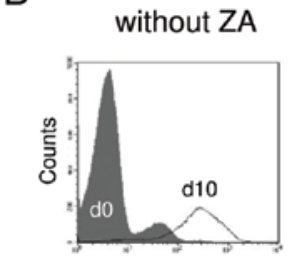
CD56 FITC
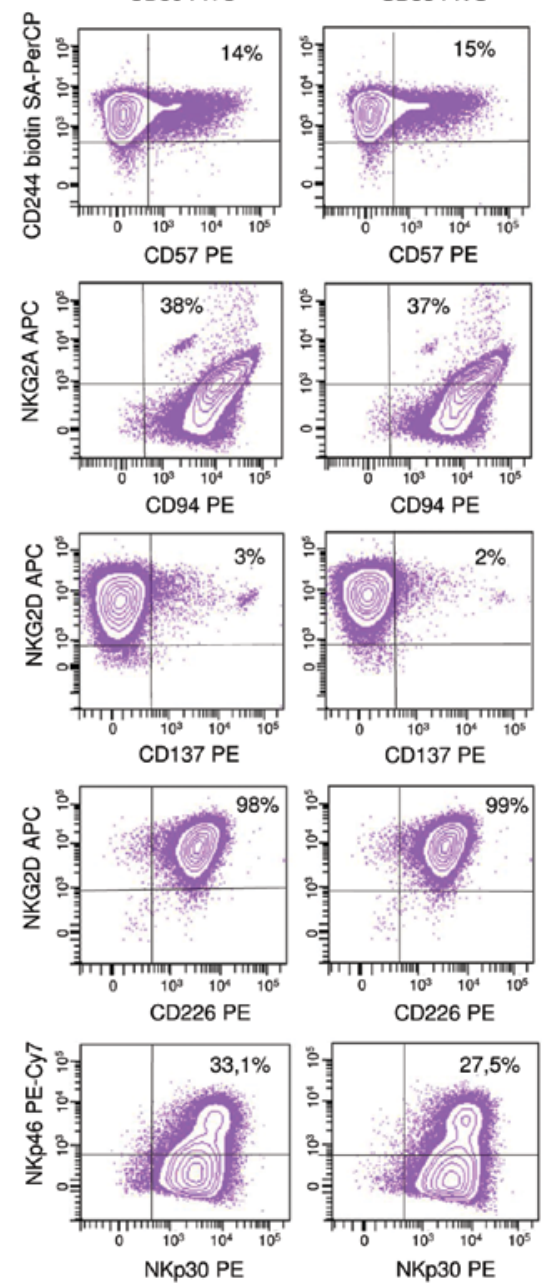

Figure 2. Phenotype and functionality of NK cell populations expanded in the presence or absence of ZA. (A) PBMCs from five healthy donors were cocultured for 10 days with irradiated K562-mb15-41BBL cells and rhIL-2 in the presence of $0.1,1$ and $10 \mu \mathrm{M}$ ZA or with medium alone, and the absolute numbers of NK cells were calculated after staining of viable cells with CD3- and CD56-specific antibodies. (B) Immunophenotyping of NK cells following 10 days of expansion in the absence (left panel) or presence (right panel) of $1 \mu \mathrm{M} \mathrm{ZA}$. The initial gate was set on CD56 $6^{+} \mathrm{CD}^{-}$cells. Shown is a representative experiment with one of three donors. (C) NK cells were in vitro expanded for 10 days in the absence or presence of $0.1,1$ and $10 \mu \mathrm{M} \mathrm{ZA}$ or with medium alone, then co-incubated with K562, ML2, VH-64 and WE-68 target cells or in medium alone for $4 \mathrm{~h}$ at a 0.1:1 stimulator-to-responder cell ratio. CD107a-expressing cells among the $\mathrm{CD}^{2} 6^{+} \mathrm{NK}$ cells were determined by flow cytometry. Shown are triplicate values obtained for one of five representative healthy donors. (D) NK cells were positively selected from peripheral blood and co-incubated with target cells for $4 \mathrm{~h}$ at an 0.1:1 stimulator-to-responder cell ratio in the absence or presence of the indicated concentrations of ZA, followed by quantification of CD107a-expressing cells among the CD56 ${ }^{+}$NK cells by flow cytometry. Shown are the combined means and standard deviations derived from triplicate wells from three healthy donors.

To address the effect of ZA on the in vitro functionality of NK cells, we compared CD107a upregulation by NK cells expanded either in the presence or absence of ZA in response to stimulation with K562 or tumor cells. Zoledronic acid is a strong activator of $\gamma \delta \mathrm{T}$ cells (20). Therefore, to avoid confounding effects by co-expanded $\gamma \delta \mathrm{T}$ cells, these cells were depleted prior to expansion by magnetic cell sorting. In the presence of 0.1 and $1 \mu \mathrm{M} \mathrm{ZA}$, potent degranulation responses to K562 and VH-64 cells and intermediate responses to WE-68 cells were maintained (Fig. 2C). In two of the five donors, responses to K562 and VH-64 cells by NK cells were reduced when the highest concentration $(10 \mu \mathrm{M})$ of ZA was added to the 4-h co-incubation.

We further investigated the effects of ZA on the functionality of native NK cells obtained by isolation from peripheral blood of three healthy donors without prior stimulation. NK cells were positively selected by magnetic cell selection, then co-incubated for $4 \mathrm{~h}$ with the various target cells at an 0.1:1 stimulator-to-responder cell ratio in the presence or absence of ZA. CD107a expression of non-activated NK cells from 
A

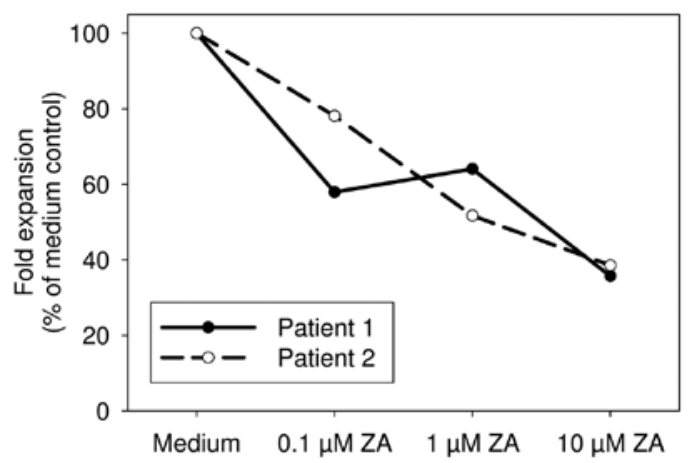

B
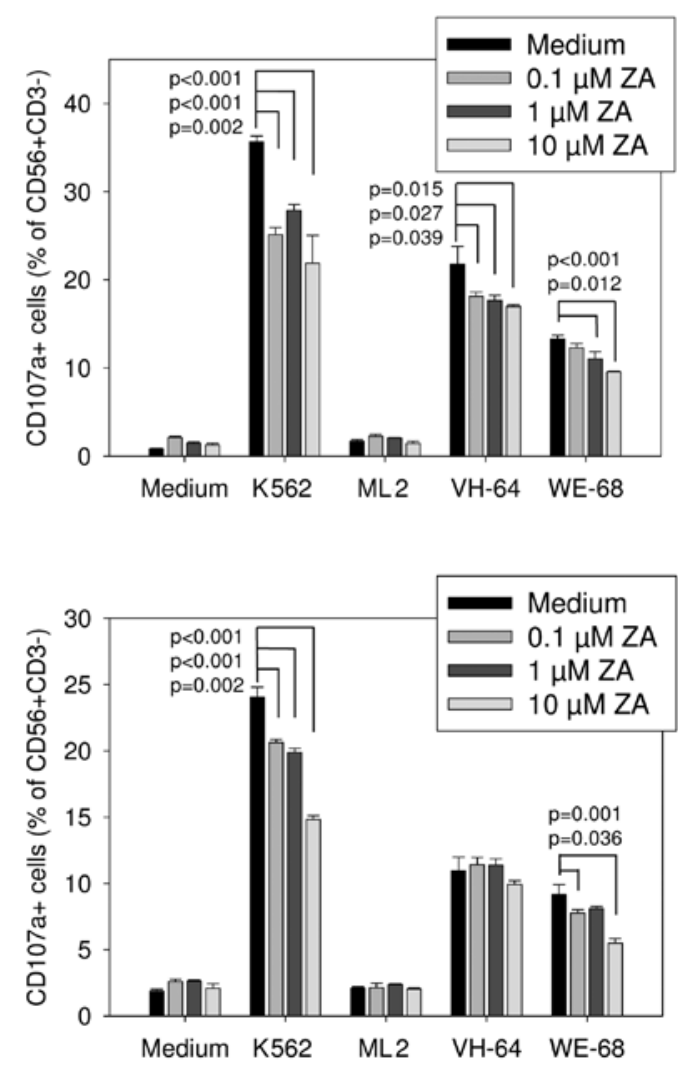

Figure 3. Expansion and functionality of NK cell populations in the presence or absence of ZA. (A) PBMCs from two Ewing sarcoma patients were cocultured for 10 days with irradiated K562-mb15-41BBL cells and rhIL-2 in the presence of $0.1,1$ and $10 \mu \mathrm{M} \mathrm{ZA}$ or with medium alone, and the absolute numbers of NK cells were calculated after staining of viable cells with CD3and CD56-specific antibodies. (B) On day 10 following in vitro expansion in the absence or presence of $0.1,1$ and $10 \mu \mathrm{M} \mathrm{ZA}$, NK cells from two Ewing sarcoma patients were co-incubated with K562, ML2, VH-64 and WE-68 target cells or in medium alone for $4 \mathrm{~h}$ at an 0.1:1 stimulator-to-responder cell ratio. The proportions of CD107a-expressing cells among the CD $56^{+} \mathrm{NK}$ cells were determined by flow cytometry. Shown are triplicate values for both donors.

all donors did not exceed background expression even upon co-incubation with K562 targets (Fig. 2D). These results were unaffected by the presence of ZA.

Thus, whereas in vitro expansion of NK cells from healthy donors was significantly impaired in the presence of ZA, their phenotype and activating receptor expression were unaffected by the drug, and degranulation responses of activated NK cells to tumor targets were maintained at ZA concentrations reflecting pharmaceutical serum levels.
Zoledronic acid impairs both in vitro expansion and degranulation responses of $N K$ cells from patients with Ewing sarcoma. To determine the effects of ZA on the functionality of NK cells from Ewing sarcoma patients, PBMCs were obtained from two patients with relapsed refractory disease. NK cells from both patients were in vitro stimulated and expanded using the above-described technique, with 0.1 to $10 \mu \mathrm{M}$ of ZA added during expansion. NK cells were effectively expanded after in vitro activation from both donors with a median 28.7-fold increase in $\mathrm{CD}^{+} 6^{+} \mathrm{CD}^{-} \mathrm{NK}$ cells (range, 27.56-29.8) and a mean purity of $88.1 \%$ (range, 80.5-95.6\%). Similar to the healthy donors, expansion of NK cells from both patients was significantly diminished in the presence of 10,1 and even $0.1 \mu \mathrm{M} \mathrm{ZA}$ (Fig. 3A). Moreover, in contrast to healthy donors, NK cells expanded from Ewing sarcoma patients in the presence of even low concentrations of 1 and $0.1 \mu \mathrm{M} \mathrm{ZA}$ had significantly impaired degranulation responses to both K562 cells and several Ewing sarcoma targets (Fig. 3B). Thus, ZA negatively affects both in vitro expansion and cytolytic antitumor activity of activated NK cells from Ewing sarcoma patients.

\section{Discussion}

ZA has attracted recent interest as a non-cytotoxic anticancer drug and is under clinical investigation for use in various diseases, including primary bone tumors (3,4,7-9). Promising features of ZA include the observed anticancer synergies between bisphosphonates and cytotoxic chemotherapies $(4,30)$, the favorable toxicity profile, and the proposed effect on the tumor-promoting bone/bone marrow microenvironment to prevent dissemination. However, drug therapy alone is unlikely to completely eliminate residual disease in patients with high-risk disseminated tumors. Instead, the combination of anticancer drugs and immune-based treatments is an attractive strategy to overcome drug resistance and clonal escape. Rational synergistic combinations may exploit the capacity of individual drugs to facilitate immune recognition of tumors by manipulation of immunogenicity and immunosuppressive effects of the microenvironment $(13,14,16)$. Potential combination partners must also be explored for their effects on the antitumor effector functions of therapeutic immune cells.

In the present study, we demonstrated that ZA significantly impeded in vitro NK cell expansion. Moreover, cytolytic NK cell responses to Ewing sarcoma cells were substantially impaired in the presence of ZA. Both effects were even more apparent with NK cells from Ewing sarcoma patients in disease-refractory situations in which such alternative combination therapies may be considered.

One of the most studied effects of ZA is the selective activation of $\gamma \delta$ T cells. ZA and other aminobisphosphonates stimulate $\gamma \delta \mathrm{T}$ cells through indirect mechanisms, including inhibition of a critical enzyme of the mevalonate metabolism. This results in accumulation of the upstream metabolite isopentenyl pyrophosphate that directly activates $\gamma \delta \mathrm{T}$ cells (31). By the same mechanism, pretreatment of solid cancer cells with ZA sensitizes cancer cells to $\gamma \delta \mathrm{T}$ cell-mediated killing (32). Apart from $\gamma \delta \mathrm{T}$ cells, ZA was reported to have profound effects on alternative immune cells, including dendritic cells (DCs) (21). Previous studies of ZA 
and NK cells have shown activating interactions $(24,33,34)$ which appear to contradict our own observations. A major conceptual difference was that these previous studies relied on the effects of ZA on accessory cells. ZA-activated $\gamma \delta \mathrm{T}$ cells and monocytes, respectively, were shown to induce NK cell cytolysis of tumor cells by providing CD137L-induced co-stimulation to upregulate NKG2D expression on $\mathrm{NK}$ cells (33) or by IFN- $\gamma$-mediated upregulation of TNF-related apoptosis-inducing ligand (TRAIL) (34). In another study, activation of NK cells in the presence of ZA was found to be a consequence of ZA-induced cytokine support by DC-like cells (24). In the present study, we investigated the effects of ZA on a population of in vitro preactivated NK cells under consideration for the cell therapy of cancer $(12,26,35)$. Preactivation relies on stimulation with the human leukemia cell line K562 and co-stimulation by 4-1BBL along with cytokine support by IL-15 and subsequent low-dose IL-2. This method results in an enrichment of highly cytotoxic NK cells with strong potency against tumor cells, including Ewing sarcoma $(12,35)$. Although we cannot exclude that residual non-NK cell lymphocyte populations contributed to our observations, interactions with $\gamma \delta$ T cells were avoided by depleting this subset prior to expansion.

Whereas ZA significantly suppressed activation-induced expansion of NK cells in most donors and in both Ewing sarcoma patients, the phenotypes of the resulting cell populations were comparable and correspond to the in vitro activated phenotype that was previously reported for 4-1BBL-based stimulation methods $(26,36)$. A practical consequence is that PBMCs or activated and expanded NK cell products should be cryopreserved prior to ZA treatment to maximize the rates of ex vivo NK cell expansion. More relevant from the translational perspective is the negative effect on degranulation responses particularly in Ewing sarcoma patients. Although potent responses were still found even at high concentrations of ZA, clinical efficacy of NK cell therapy may be more dependent on an optimal activity of therapeutic cells, and even moderate inhibitory effects may interfere with tumor cell clearance.

The mechanisms by which ZA affects NK cell expansion and responses to target cells remain to be resolved. Cytolytic responses of activated NK cells to Ewing sarcoma targets were shown to involve interaction of the NK cell activation receptors NKG2D and DNAM-1 with their respective ligands on tumor cells $(12,37)$. Expression levels of these receptors were unaffected by ZA in our studies. Alternatively, at least the effect on degranulation responses may be explained by effects of ZA on the Ewing sarcoma target cells, e.g. by downregulation of activating receptor ligands. The variability observed among donors may be explained by the impact of allogeneic KIR (killer immunoglobulin-like receptor) mismatches on the outcome of the interaction.

Whether autologous NK cells in Ewing sarcoma patients have a role in the natural defense against this disease is unclear. In the present study, non-activated NK cells were not capable of functionally interacting with Ewing sarcoma targets, and the results were unaffected by ZA.

Collectively, our data suggest that ZA maintenance therapy in Ewing sarcoma is not an ideal platform for adoptive NK cell transfer. Drugs that potentiate the therapeutic immune effects of NK cells and the mechanisms underlying these interactions must be identified to develop effective combinations of novel drugs and cellular therapies.

\section{Acknowledgements}

This study was supported by a grant from the Dr MildredScheel Stiftung der Deutschen Krebshilfe (to C.R.) and an institutional grant by IMF Muenster.

\section{References}

1. Potratz J, Dirksen U, Jurgens H and Craft A: Ewing sarcoma: clinical state-of-the-art. Pediatr Hematol Oncol 29: 1-11, 2012.

2. Berenson JR, Lichtenstein A, Porter L, Dimopoulos MA, Bordoni R, George S, Lipton A, Keller A, Ballester O, Kovacs MJ, Blacklock HA, Bell R, et al: Efficacy of pamidronate in reducing skeletal events in patients with advanced multiple myeloma. Myeloma Aredia Study Group. N Engl J Med 22: 488-493, 1996

3. Tassone P, Tagliaferri P, Viscomi C, Palmieri C, Caraglia M, D'Alessandro A, Galea E, Goel A, Abbruzzese A, Boland CR and Venuta S: Zoledronic acid induces antiproliferative and apoptotic effects in human pancreatic cancer cells in vitro. Br J Cancer 88 : 1971-1978, 2003

4. Odri GA, Dumoucel S, Picarda G, Battaglia S, Lamoureux F, Corradini N, Rousseau J, Tirode F, Laud K, Delattre O, Gouin F, Heymann D, et al: Zoledronic acid as a new adjuvant therapeutic strategy for Ewing's sarcoma patients. Cancer Res 70: 7610-7619, 2010.

5. Zhou Z, Guan H, Duan X and Kleinerman ES: Zoledronic acid inhibits primary bone tumor growth in Ewing sarcoma. Cancer 104: 1713-1720, 2005

6. Morgan GJ, Davies FE, Gregory WM, Szubert AJ, Bell SE, Drayson MT, Owen RG, Ashcroft AJ, Jackson GH and Child JA: Effects of induction and maintenance plus long-term bisphosphonates on bone disease in patients with multiple myeloma: the Medical Research Council Myeloma IX Trial. Blood 119: 5374-5383, 2012

7. Heymann D, Ory B, Blanchard F, Heymann MF, Coipeau P, Charrier C, Couillaud S, Thiery JP, Gouin F and Redini F: Enhanced tumor regression and tissue repair when zoledronic acid is combined with ifosfamide in rat osteosarcoma. Bone 37: 74-86, 2005.

8. Aft R, Naughton M, Trinkaus K, Watson M, Ylagan L, ChavezMacGregor M, Zhai J, Kuo S, Shannon W, Diemer K, Herrmann V, Dietz J, et al: Effect of zoledronic acid on disseminated tumour cells in women with locally advanced breast cancer: an open label, randomised, phase 2 trial. Lancet Oncol 11: 421-428, 2010.

9. Zarogoulidis K, Boutsikou E, Zarogoulidis P, Eleftheriadou E, Kontakiotis T, Lithoxopoulou H, Tzanakakis G, Kanakis I and Karamanos NK: The impact of zoledronic acid therapy in survival of lung cancer patients with bone metastasis. Int J Cancer 125: 1705-1709, 2009.

10. Siddiqui T, Marsh RW, Allegra C, Whittaker D, Scarborough M, Gibbs P, Zlotecki R, Reith JD and Drane W: Effective salvage treatment of recurrent Ewing sarcoma utilizing chemotherapy and zoledronic acid. Clin Adv Hematol Oncol 8: 499-504, 2010.

11. Kalos M, Levine BL, Porter DL, Katz S, Grupp SA, Bagg A and June $\mathrm{CH}$ : $\mathrm{T}$ cells with chimeric antigen receptors have potent antitumor effects and can establish memory in patients with advanced leukemia. Sci Transl Med 3: 95ra73, 2011.

12. Cho D, Shook DR, Shimasaki N, Chang YH, Fujisaki H and Campana D: Cytotoxicity of activated natural killer cells against pediatric solid tumors. Clin Cancer Res 16: 3901-3909, 2010.

13. Begley J, Vo DD, Morris LF, Bruhn KW, Prins RM, Mok S, Koya RC, Garban HJ, Comin-Anduix B, Craft N and Ribas A: Immunosensitization with a Bcl-2 small molecule inhibitor. Cancer Immunol Immunother 58: 699-708, 2009.

14. Boni A, Cogdill AP, Dang P, Udayakumar D, Njauw CN, Sloss CM, Ferrone CR, Flaherty KT, Lawrence DP, Fisher DE, Tsao H and Wargo JA: Selective BRAFV600E inhibition enhances T-cell recognition of melanoma without affecting lymphocyte function. Cancer Res 70: 5213-5219, 2010.

15. Finke JH, Rini B, Ireland J, Rayman P, Richmond A, Golshayan A, Wood L, Elson P, Garcia J, Dreicer R and Bukowski R: Sunitinib reverses type-1 immune suppression and decreases T-regulatory cells in renal cell carcinoma patients. Clin Cancer Res 14: 6674-6682, 2008. 
16. Skov S, Pedersen MT, Andresen L, Straten PT, Woetmann A and Odum N: Cancer cells become susceptible to natural killer cell killing after exposure to histone deacetylase inhibitors due to glycogen synthase kinase-3-dependent expression of MHC class I-related chain A and B. Cancer Res 65: 11136-11145, 2005.

17. Berghuis D, Schilham MW, Vos HI, Santos SJ, Kloess S, Buddingh EP, Egeler RM, Hogendoorn PC and Lankester AC: Histone deacetylase inhibitors enhance expression of NKG2D ligands in Ewing sarcoma and sensitize for natural killer cellmediated cytolysis. Clin Sarcoma Res 2: 8, 2012.

18. Fraser CK, Blake SJ, Diener KR, Lyons AB, Brown MP, Hughes TP and Hayball JD: Dasatinib inhibits recombinant viral antigen-specific murine $\mathrm{CD} 4^{+}$and $\mathrm{CD} 8^{+} \mathrm{T}$-cell responses and NK-cell cytolytic activity in vitro and in vivo. Exp Hematol 37: 256-265, 2009.

19. Rossi LE, Avila DE, Spallanzani RG, Ziblat A, Fuertes MB, Lapyckyj L, Croci DO, Rabinovich GA, Domaica CI and Zwirner NW: Histone deacetylase inhibitors impair NK cell viability and effector functions through inhibition of activation and receptor expression. J Leukoc Biol 91: 321-331, 2012.

20. Mariani S, Muraro M, Pantaleoni F, Fiore F, Nuschak B, Peola S, Foglietta M, Palumbo A, Coscia M, Castella B, Bruno B, Bertieri $\mathrm{R}$, et al: Effector gamma delta $\mathrm{T}$ cells and tumor cells as immune targets of zoledronic acid in multiple myeloma. Leukemia 19: 664-670, 2005.

21. Bringmann A, Schmidt SM, Weck MM, Brauer KM, von Schwarzenberg K, Werth D, Grünebach F and Brossart P: Zoledronic acid inhibits the function of Toll-like receptor 4 ligand activated monocyte-derived dendritic cells. Leukemia 21 : $732-738,2007$.

22. Pecherstorfer M, Jilch R, Sauty A, Horn E, Keck AV, Zimmer-Roth I and Thiebaud D: Effect of first treatment with aminobisphosphonates pamidronate and ibandronate on circulating lymphocyte subpopulations. J Bone Miner Res 15: 147-154, 2000 .

23. Liote F, Boval-Boizard B, Fritz P and Kuntz D: Lymphocyte subsets in pamidronate-induced lymphopenia. Br J Rheumatol 34: 993-995, 1995.

24. Nussbaumer O, Gruenbacher G, Gander $\mathrm{H}$ and Thurnher $\mathrm{M}$ DC-like cell-dependent activation of human natural killer cells by the bisphosphonate zoledronic acid is regulated by $\gamma \delta \mathrm{T}$ lymphocytes. Blood 118: 2743-2751, 2011.

25. Ottaviano L, Schaefer KL, Gajewski M, Huckenbeck W, Baldus S, Rogel U, Mackintosh C, de Alava E, Myklebost O, Kresse SH, Meza-Zepeda LA, Serra M, et al: Molecular characterization of commonly used cell lines for bone tumor research: a trans-European EuroBoNet effort. Genes Chromosomes Cancer 49: 40-51, 2010

26. Imai C, Iwamoto S and Campana D: Genetic modification of primary natural killer cells overcomes inhibitory signals and induces specific killing of leukemic cells. Blood 106: 376-383, 2005 .
27. Alter G, Malenfant JM and Altfeld M: CD107a as a functional marker for the identification of natural killer cell activity. $\mathrm{J}$ Immunol Methods 294: 15-22, 2004

28. Chen T, Berenson J, Vescio R, Swift R, Gilchick A, Goodin S, LoRusso P, Ma P, Ravera C, Deckert F, Schran H, Seaman J, et al: Pharmacokinetics and pharmacodynamics of zoledronic acid in cancer patients with bone metastases. J Clin Pharmacol 42: 1228-1236, 2002.

29. Lopez-Verges S, Milush JM, Pandey S, York VA, ArakawaHoyt J, Pircher H, Norris PJ, Nixon DF and Lanier LL: CD57 defines a functionally distinct population of mature NK cells in the human CD56 ${ }^{\mathrm{dim}} \mathrm{CD} 16^{+} \mathrm{NK}$-cell subset. Blood 116: 3865-3874, 2010.

30. Coleman RE, Winter MC, Cameron D, Bell R, Dodwell D, Keane MM, Gil M, Ritchie D, Passos-Coelho JL, Wheatley D, Burkinshaw R, Marshall SJ, et al: The effects of adding zoledronic acid to neoadjuvant chemotherapy on tumour response: exploratory evidence for direct anti-tumour activity in breast cancer. Br J Cancer 102: 1099-1105, 2010.

31. Wang H, Sarikonda G, Puan KJ, Tanaka Y, Feng J, Giner JL, Cao R, Monkkonen J, Oldfield E and Morita CT: Indirect Stimulation of Human $\mathrm{V} \gamma 2 \mathrm{~V} \delta 2 \mathrm{~T}$ cells through alterations in isoprenoid metabolism. J Immunol 187: 5099-5113, 2011.

32. Marcu-Malina V, Heijhuurs S, van Buuren M, Hartkamp L, Strand S, Sebestyen Z, Scholten K, Martens A and Kuball J: Redirecting $\alpha \beta \mathrm{T}$ cells against cancer cells by transfer of a broadly tumor-reactive $\gamma \delta \mathrm{T}$-cell receptor. Blood 118: 50-59, 2011.

33. Maniar A, Zhang X, Lin W, Gastman BR, Pauza CD, Strome SE and Chapoval AI: Human $\gamma \delta$ T lymphocytes induce robust NK cell-mediated antitumor cytotoxicity through CD137 engagement. Blood 116: 1726-1733, 2010.

34. Sarhan D, D'Arcy P, Wennerberg E, Liden M, Hu J, Winqvist O, Rolny $\mathrm{C}$ and Lundqvist A: Activated monocytes augment TRAIL-mediated cytotoxicity by human NK cells through release of IFN-gamma. Eur J Immunol: Sep 19, 2012 (Epub ahead of print)

35. Fujisaki H, Kakuda H, Shimasaki N, Imai C, Ma J, Lockey T, Eldridge P, Leung WH and Campana D: Expansion of highly cytotoxic human natural killer cells for cancer cell therapy. Cancer Res 69: 4010-4017, 2009.

36. Dowell AC, Oldham KA, Bhatt RI, Lee SP and Searle PF: Long-term proliferation of functional human NK cells, with conversion of CD56(dim) NK cells to a CD56 (bright) phenotype, induced by carcinoma cells co-expressing 4-1BBL and IL-12. Cancer Immunol Immunother 61: 615-628, 2012

37. Verhoeven DH, de Hooge AS, Mooiman EC, Santos SJ, ten Dam MM, Gelderblom H, Melief CJ, Hogendoorn PC, Egeler RM, van Tol MJ, Schilham MW and Lankester AC: NK cells recognize and lyse Ewing sarcoma cells through NKG2D and DNAM-1 receptor dependent pathways. Mol Immunol 45: 3917-3925, 2008. 